\title{
A Corrosion Resistant Sintered Stainless Steel: Type 304L Containing Mo-Rich Phases
}

\author{
Haruka Saito*, Izumi Muto and Yu Sugawara \\ Department of Materials Science, Graduate School of Engineering, Tohoku University, Sendai 980-8579, Japan
}

Pure Mo and type 304L stainless steel powders were mixed to form type 304L with 2.5 mass $\%$ Mo and were subsequently sintered to fabricate a stainless steel containing Mo-rich phases. After sintering, heat treatments were performed at $1573 \mathrm{~K}(5 \mathrm{~h})$ and $1373 \mathrm{~K}(0.5 \mathrm{~h})$. It was confirmed that Mo- and Cr-enriched secondary phases were generated. Potentiodynamic polarization was conducted in $0.1 \mathrm{M} \mathrm{NaCl}$. The pitting potential of the stainless steel containing Mo-rich phases was higher than that of the commercial type 316L sheet (non-sintered steel). The results of this study clearly indicate that the existence of Mo-rich phases in sintered stainless steels improves their pitting corrosion resistance, making them highly suitable for use in chloride environments. [doi:10.2320/matertrans.MT-M2020228]

(Received July 22, 2020; Accepted August 21, 2020; Published October 2, 2020)

Keywords: stainless steel, pitting corrosion, molybdenum

\section{Introduction}

It is well-known that Mo improves the pitting corrosion resistance of stainless steels. ${ }^{1-3)}$ This has been mainly attributed to the existence of Mo-species in passive films, ${ }^{2,4-9)}$ and to the inhibition effect of the dissolved Mospecies. ${ }^{10-14)}$ For instance, Montemor et al. proposed that Mo exists as Mo(IV), Mo(VI), and/or metallic Mo in the oxide films on stainless steels. ${ }^{4}$ Kimura et al. demonstrated that the formation of $\mathrm{MoO}_{4}{ }^{2-}$ networks near the dissolving metal interface enhances the pitting corrosion resistance of stainless steel. ${ }^{13)}$ There is no unified theory about the role of Mo.

In this study, to derive a new concept for corrosion resistant stainless steels, the steel that contains Mo-rich phases was fabricated by spark plasma sintering, ${ }^{15,16)}$ and its pitting corrosion resistance was measured electrochemically.

\section{Experimental}

\subsection{Specimens}

Spark plasma sintering (SPS) was used for the fabrication of type 304L containing Mo-rich phases. Mo powders (particle size: $3-5 \mu \mathrm{m}, 99.9$ mass $\%$ pure) and gas atomized type $304 \mathrm{~L}$ powders were used as the starting materials. The chemical composition of the type $304 \mathrm{~L}$ powders is listed in Table 1. Mo powders were ball-milled for $1 \mathrm{~h}$ at $400 \mathrm{rpm}$. After milling, Mo powders (0.175 g, 2.5 mass\%) were mixed with type $304 \mathrm{~L}$ powders $(6.825 \mathrm{~g})$. The mass percentage of the Mo powders was almost the same as the Mo concentration in a conventional type $316 \mathrm{~L}$ stainless steel. The mixed powders $(\mathrm{ca} .7 \mathrm{~g})$ were packed into a cylindrical graphite die (diameter of $15 \mathrm{~mm}$ ), and the powders were heated in vacuum from room temperature to $1373 \mathrm{~K}$ over $20 \mathrm{~min}$ and then were maintained at $1373 \mathrm{~K}$ for $20 \mathrm{~min}$. After that, the sintered specimens were cooled to room temperature. After sintering, the specimens were heat-treated at $1573 \mathrm{~K}$ for $5 \mathrm{~h}$ in vacuum and quenched in water. Then, a solution-treatment was conducted at $1373 \mathrm{~K}$ for $0.5 \mathrm{~h}$ (water quench).

*Graduate Student, Tohoku University. Corresponding author, E-mail haruka.saito.s8@dc.tohoku.ac.jp
Sintered types $304 \mathrm{~L}$ and $316 \mathrm{~L}$ samples were also fabricated by SPS. Gas-atomized types 304L and 316L powders were used as the starting materials. The chemical composition of type $316 \mathrm{~L}$ powders is also listed in Table 1. The same SPS procedure was applied. After sintering, only a solution treatment was conducted at $1373 \mathrm{~K}$ for $0.5 \mathrm{~h}$ (water quench).

The as-sintered specimens had a cylindrical shape. The diameter and thickness were $15 \mathrm{~mm}$ and $5 \mathrm{~mm}$, respectively. After the solution heat-treatment, the specimens were sliced in half, and the sliced surfaces were polished down to $1 \mu \mathrm{m}$ using a diamond paste and were ultrasonically cleaned with ethanol.

As reference materials, commercial types 304 and 316L sheets (non-sintered steels) were used. The chemical compositions of these steels are also listed in Table 1. The solution-treatment was conducted at $1373 \mathrm{~K}$ for $0.5 \mathrm{~h}$ (water quench). The surfaces of these materials were also polished down to $1 \mu \mathrm{m}$ using a diamond paste. In this study, the specimens fabricated by SPS were labeled as type 304L (SPS), type 316L (SPS), and type 304L containing Mo-rich phases (SPS) to avoid confusion with non-sintered steels.

\subsection{Polarization measurements}

Potentiodynamic polarization was conducted in a $0.1 \mathrm{M}$ $\mathrm{NaCl}$ solution ( $\mathrm{pH}$ 6.0) under naturally aerated conditions at $298 \mathrm{~K}$. The scan rate was set at $23 \mathrm{mV} \mathrm{min}^{-1}$. All of the reported potentials are in reference to $\mathrm{Ag} / \mathrm{AgCl}(3.33 \mathrm{M} \mathrm{KCl})$.

\subsection{Observations and analysis}

The specimens were etched in a mixture of $\mathrm{HNO}_{3}$ and $\mathrm{HCl}$ for $30 \mathrm{~s}$, and their microstructures were observed. The aspolished surfaces of the specimens were also analyzed using a scanning electron microscope (SEM) equipped with an electron probe micro analyzer (EPMA). The acceleration voltage was set at $15 \mathrm{kV}$.

\subsection{X-ray diffraction analysis}

$\mathrm{Cu}-\mathrm{K} \alpha$ radiation with a Ni-filter was used. Diffraction patterns were collected over a $2 \theta$ range of $15-90^{\circ}$ with a step width of $0.02^{\circ}$. The scan rate was $1^{\circ} \mathrm{min}^{-1}$. The peaks related to $\mathrm{K} \alpha 2$ were subtracted using computer software. 
Table 1 Chemical compositions of the specimens.

\begin{tabular}{|c|c|c|c|c|c|c|c|}
\hline & $\mathrm{C}$ & $\mathrm{Si}$ & $\mathrm{Mn}$ & $\mathrm{P}$ & $\mathrm{S}$ & $\mathrm{Ni}$ & $\mathrm{Cr}$ \\
\hline 304L powder & 0.010 & 0.22 & 0.17 & 0.012 & 0.0025 & 11.13 & 19.01 \\
\hline $16 \mathrm{Lp}$ & 0.015 & 0.90 & 0.69 & 0.011 & 0.0039 & 12 & 17.60 \\
\hline 04 sheet & 0.035 & 0.38 & 0.84 & 0.031 & 0.0004 & 9.00 & 18.07 \\
\hline \multirow[t]{2}{*}{$316 \mathrm{~L}$ sheet } & 0.016 & 0.41 & 0.84 & 0.026 & 0.0009 & 10.02 & 16.50 \\
\hline & Mo & $\mathrm{Cu}$ & $\mathrm{Ti}$ & $\mathrm{Al}$ & $\mathrm{Nb}$ & $\mathrm{O}$ & $\mathrm{N}$ \\
\hline $04 \mathrm{~L}$ & 0.01 & 0.01 & 0.001 & 0.002 & 0.007 & & \\
\hline $16 \mathrm{~L} \mathrm{p}$ & 2.10 & 0.03 & 0.002 & 0.003 & 0.001 & & \\
\hline 304 sheet & 0.23 & 0.30 & 0.002 & 0.028 & & 0.0 & 0.033 \\
\hline $16 \mathrm{~L}$ sheet & 2.03 & 0.21 & 0.002 & 0.004 & 0.041 & 0.002 & 0.041 \\
\hline
\end{tabular}

\section{Results and Discussion}

\subsection{Microstructure characterization}

The microstructures of the specimens were inspected. Figure 1 shows the optical micrographs of the etched surfaces of type 304L containing Mo-rich phases (SPS) and type 316L (SPS). The many black spots (blue arrows) observed. These spots are the voids formed in the sintering process. Moreover, large round phases can be clearly observed at the positions indicated by the red arrows; these represent the secondary phases. Black spots were also observed on type 316L (SPS), as shown in Fig. 1(b). However, unlike for type 304L containing Mo-rich phases (SPS), no secondary phase was observed on type $316 \mathrm{~L}$ (SPS). This implies that the Mo in type 316L (SPS) exists uniformly as a solid solution in the steel matrix.

To determine the composition of the secondary phases, SEM/EPMA analysis was conducted. Figure 2(a) shows

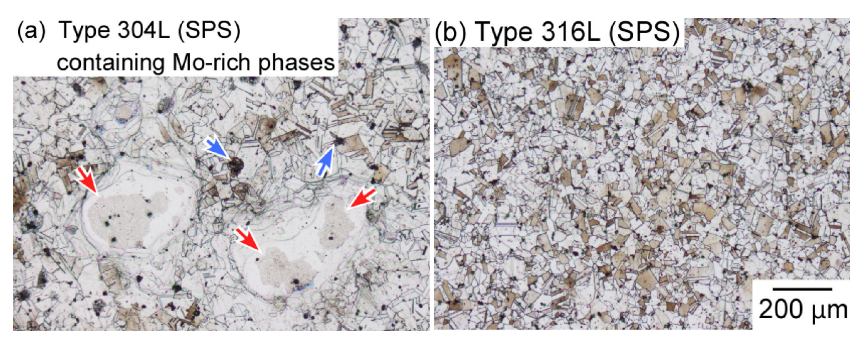

Fig. 1 Optical micrographs of the as-polished surfaces of the specimens fabricated by spark plasma sintering: (a) type 304L containing Mo-rich phases and (b) type 316L.
SEM image of the as-polished surface of type 304L containing Mo-rich phases (SPS) and the corresponding EPMA maps. Mo-rich areas can clearly be observed in the EPMA maps. The results of EPMA point analysis at points 1 and 2 are summarized in Table 2. At point 1 (Mo-rich area), the relative concentrations of $\mathrm{Mo}$ and $\mathrm{Cr}$ were 3.2 and 24.2 mass \%, respectively. By contrast, the relative concentrations of Mo and $\mathrm{Cr}$ at point 2 (Mo-poor area) were 1.7 and 18.4 mass \%, respectively. The Mo-rich areas correspond to the secondary phases in Fig. 1(a) and were generated from the Mo powders.

Figure 2(b) shows SEM image of the as-polished surface of type $316 \mathrm{~L}$ (SPS) and the corresponding EPMA maps. Local accumulation was not detected neither for Mo nor for Cr. As listed in Table 2, the relative concentrations of Mo and $\mathrm{Cr}$ at point 3 were 2.1 and 18.0 mass $\%$, respectively. The concentration of $\mathrm{Ni}$ at point 3 was 12.4 mass $\%$. Therefore, the type 316L (SPS) prepared in this study was a typical type $316 \mathrm{~L}$ stainless steel.

To determine the lattice structure of the Mo-rich phases, XRD analysis was conducted. Figure 3 shows the XRD patterns of the Mo powders, type $304 \mathrm{~L}$ powders, and

Table 2 Relative concentration at points 1-3 in Fig. 2 (mass\%).

\begin{tabular}{ccccc}
\hline Point & $\mathrm{Fe}$ & $\mathrm{Cr}$ & $\mathrm{Ni}$ & $\mathrm{Mo}$ \\
\hline 1 & 65.7 & 24.2 & 6.4 & 3.2 \\
2 & 68.7 & 18.4 & 11.2 & 1.7 \\
3 & 66.6 & 18.0 & 12.4 & 2.1 \\
\hline
\end{tabular}

(a) Type $304 \mathrm{~L}$ containing Mo-rich phases (SPS)
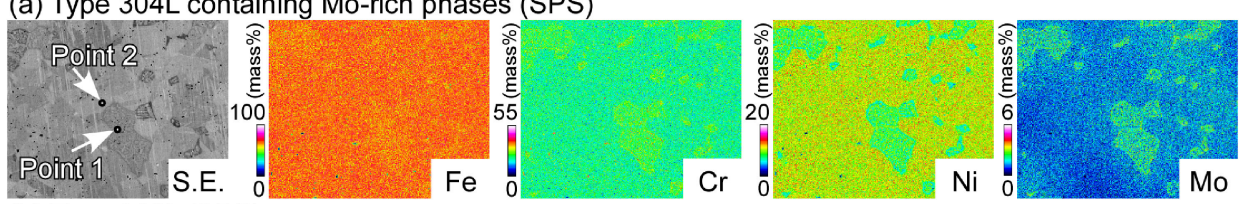

(b) Type 316L (SPS)
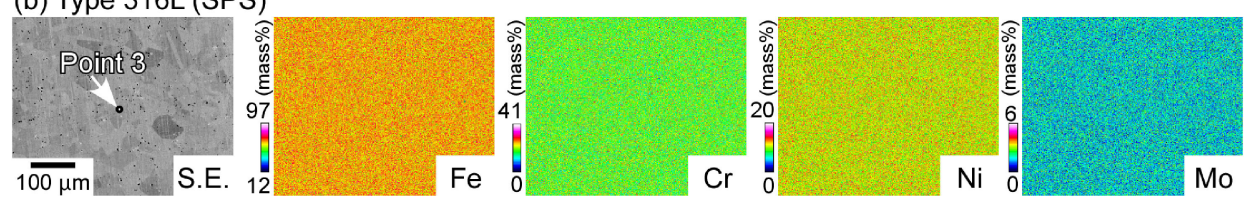

Fig. 2 SEM image and corresponding EPMA maps of the as-polished surfaces of the specimens fabricated by spark plasma sintering:

(a) type $304 \mathrm{~L}$ containing Mo-rich phases and (b) type $316 \mathrm{~L}$. 


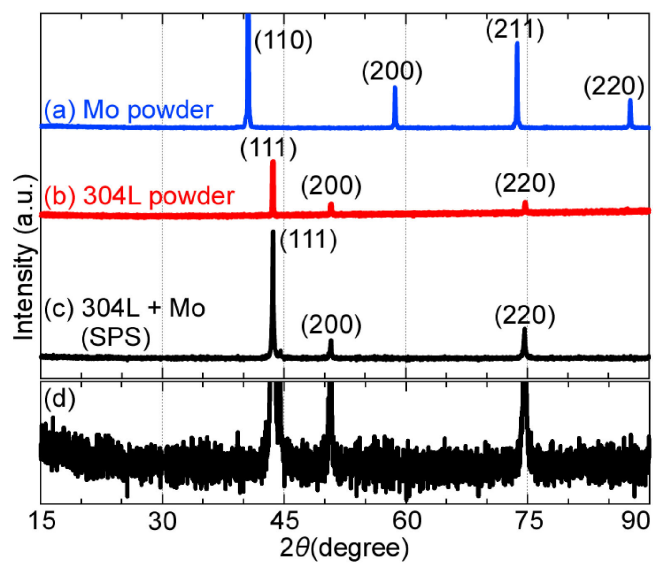

Fig. 3 XRD patterns of (a) as-received Mo powder, (b) as-received type 304L powder, (c) type 304L containing Mo-rich phases (SPS), and (d) a magnified view of (c).

type 304L containing Mo-rich phases (SPS). For Mo powders, the main peak was detected at $40.587^{\circ}$, and three distinct peaks were observed at $58.646^{\circ}, 73.742^{\circ}$, and $87.688^{\circ}$. The main peak and the other peaks were assigned to the (110), (200), (211), and (220) reflections of bcc-Mo. For the type $304 \mathrm{~L}$ powders, the peaks appeared at $43.631^{\circ}$, $50.809^{\circ}$, and $74.730^{\circ}$. These peaks correspond to the (111), (200), and (220) reflections of the fcc structure. For type $304 \mathrm{~L}$ containing Mo-rich phases (SPS), the peaks were observed at $43.631^{\circ}, 44.577^{\circ}, 50.768^{\circ}$, and $74.627^{\circ}$. These positions were almost the same as those observed for the type $304 \mathrm{~L}$ powders. Even in the enlarged view of the XRD pattern shown in Fig. 3(d), there are no peaks corresponding to bcc-Mo. While it is possible that Mo-rich phases have an fcc structure, it is also possible that the amount of the bcc Mo-rich phases is below the detection limit.

Based on the above results, for precision, type 304L containing Mo-rich phases (SPS) should be referred to as type 304L containing Mo- and Cr-rich phases (SPS). For simplicity, this sintered steel is referred to as type 304L containing Mo-rich phases (SPS).

\subsection{Pitting corrosion resistance}

To assess the pitting corrosion resistance, potentiodynamic polarization was performed. Figure 4 shows the anodic polarization curves of type 304L containing Mo-rich phases (SPS) in $0.1 \mathrm{M} \mathrm{NaCl}$. The experiments were conducted three times to confirm reproducibility. In the first run, many current spikes were generated in the passive region, but no continuous increase in the current density was observed. In this case, the increase in the current density above $1.2 \mathrm{~V}$ was due to the oxygen evolution reaction, and no stable pitting was generated. In the second run, a large current increase was observed from 0.1 to $0.4 \mathrm{~V}$. However, the current density suddenly decreased to the passive current density at $c a .0 .4 \mathrm{~V}$. The next large increase in the current density at $c a .0 .7 \mathrm{~V}$ was due to stable pit initiation. The polarization behavior of the third run was almost the same as that of the second run. Based on this figure, the pitting potential of type $304 \mathrm{~L}$ containing Mo-rich phases (SPS) was determined to be above $0.7 \mathrm{~V}$.

Figure 5 shows the polarization curves of type 316L (SPS) in $0.1 \mathrm{M} \mathrm{NaCl}$. As a reference, the polarization curve of

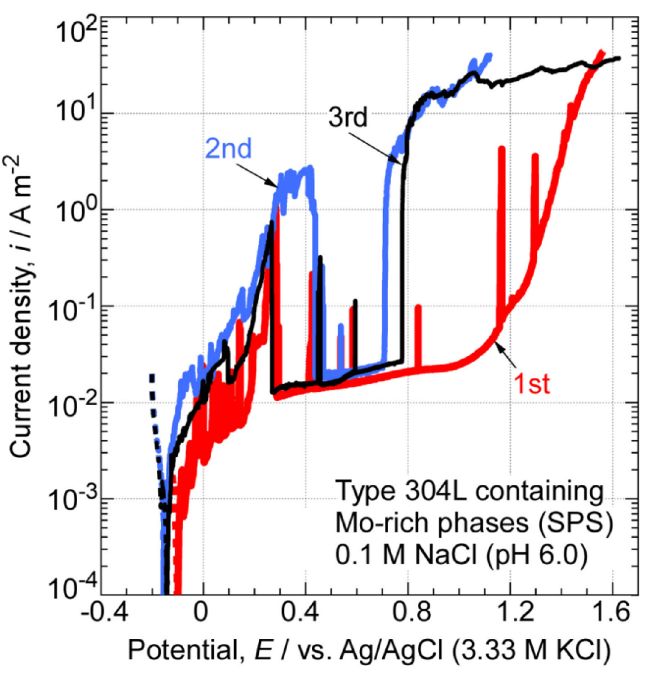

Fig. 4 Anodic polarization curves of type 304L containing Mo-rich phases (SPS) in naturally aerated $0.1 \mathrm{M} \mathrm{NaCl}$ at $\mathrm{pH} 6.0(298 \mathrm{~K})$.

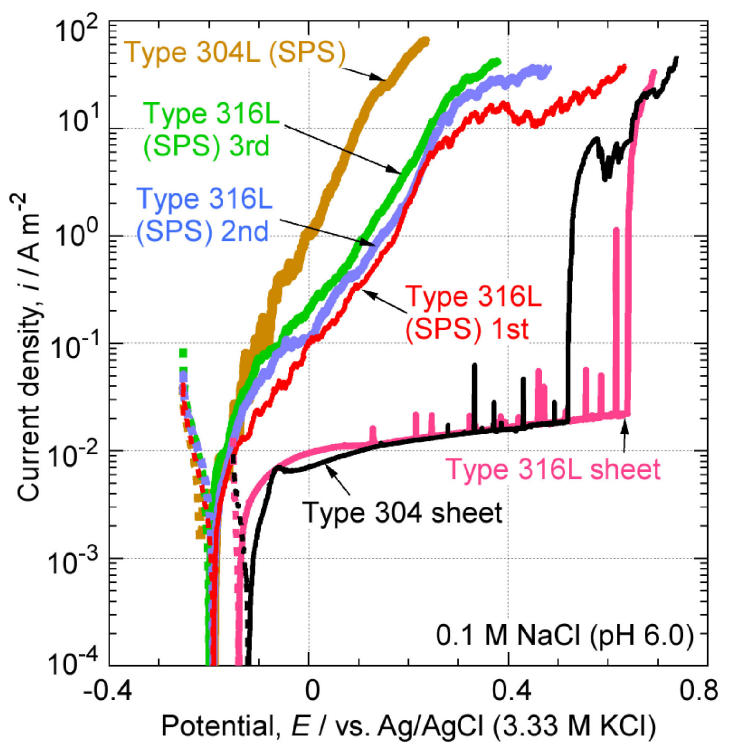

Fig. 5 Anodic polarization curves of type 304L fabricated by SPS, type $316 \mathrm{~L}$ fabricated by SPS, commercial type 304 sheet, and commercial type $316 \mathrm{~L}$ sheet in naturally aerated $0.1 \mathrm{M} \mathrm{NaCl}$ at pH $6.0(298 \mathrm{~K})$.

type 304L (SPS) is also included in the figure along with the potentiodynamic anodic polarization curves of the nonsintered steels (commercial type 304 and $316 \mathrm{~L}$ sheets). Polarization measurements were conducted three times for type 316L (SPS). In all cases, the current density increased with electrode potential, and no passivation occurred. After polarization, pitting corrosion was observed, and the current increases were determined to be due to the initiation and growth of pitting. Similar polarization behavior was observed for type 304L (SPS). A comparison of these two sintered steels indicates that the presence of Mo in the solid solution did not lead to any changes in the current density. This is likely due to the existence of the voids since passive regions were obtained in the polarization curves in the non-sintered steels (commercial type 304 and 316L sheets), and the pitting potential increased due to Mo-alloying. It was concluded that the voids were the origin of the observed decrease in the pitting potentials, and that there was no or little beneficial 
effect of Mo-alloying on the pitting corrosion resistance of the sintered stainless steels. By contrast, as shown in Fig. 4, the passive region was clearly observed on type 304L containing Mo-rich phases (SPS). It should be noted that the pitting potential of this steel was higher than that of commercial type $316 \mathrm{~L}$ sheet shown in Fig. 5. The pitting potential of type 304 and $316 \mathrm{~L}$ sheets were $c a .0 .5 \mathrm{~V}$ and $c a$. $0.6 \mathrm{~V}$, respectively. By contrast, the pitting potential for type 304L containing Mo-rich phases (SPS) was determined to be above $0.7 \mathrm{~V}$. It was found that the inhibition effect of Mo-rich phases on pitting corrosion was much higher than that of the Mo in the solid solution in the steel matrix. As mentioned above, also in the case of type 304L containing Mo-rich phases (SPS), the initiation sites of pitting were expected to be the voids. After pit initiation, it seems that the growth of pitting was effectively inhibited by the Mo-rich phases when the pits reached the Mo-rich phases. It is possible that the dissolved Mo-species from the Mo-rich phases prevent the pit growth. Furthermore, the dissolution rate of the Mo-rich phases is expected to be low and such a low rate give rise to the repassivation inside the pits. Further study is needed to determine the pitting corrosion inhibition mechanism of the Mo-rich phases where $\mathrm{Cr}$ is accumulated. Nevertheless, it can be concluded that the existence of Mo-rich phases in sintered stainless steels inhibits pitting growth.

\section{Conclusions}

(1) Pure Mo and type 304L powders were mixed for the formation of type $304 \mathrm{~L}$ with 2.5 mass $\%$ Mo and subsequently sintered and heat-treated. It was confirmed that Mo- and Cr-enriched secondary phases were generated.

(2) In $0.1 \mathrm{M} \mathrm{NaCl}$, the pitting potential of type 304L containing Mo-rich phases (SPS) was higher than that of commercial type $316 \mathrm{~L}$ sheet.

\section{REFERENCES}

1) A.J. Sedriks: Corrosion of Stainless Steels, (Wiley-Interscience, New York, 1996) pp. 111-125.

2) K. Sugimoto and Y. Sawada: Corros. Sci. 17 (1977) 425-445.

3) M. Nishimoto, I. Muto, Y. Sugawara and N. Hara: J. Electrochem. Soc. 166 (2019) C3081-C3089.

4) M.F. Montemor, A.M.P. Simões, M.G.S. Ferreira and M.D.C. Belo: Corros. Sci. 41 (1999) 17-34.

5) G. Tranchida, F.D. Franco and M. Santamaria: J. Electrochem. Soc. 167 (2020) 061506.

6) K. Hashimoto, K. Asami, A. Kawashima, H. Habazaki and E. Akiyama: Corros. Sci. 49 (2007) 42-52.

7) V. Maurice, H. Peng, L.H. Klein, A. Seyeux, S. Zanna and P. Marcus: Faraday Discuss. 180 (2015) 151-170.

8) L. Jinlong, L. Tongxiang and W. Chen: Mater. Lett. 171 (2016) 38-41.

9) A. Pardo, M.C. Merino, A.E. Coy, F. Viejo, R. Arrabal and E. Matykina: Corros. Sci. 50 (2008) 780-794.

10) W.J. Tobler and S. Virtanen: Corros. Sci. 48 (2006) 1585-1607.

11) K. Jung, S. Ahn, Y. Kim, S. Oh, W. Ryu and H. Kwon: Corros. Sci. 140 (2018) 61-72.

12) L. An, J. Cao, L. Wu, H. Mao and Y. Yang: J. Iron Steel Res. Int. 23 (2016) 1333-1341.

13) M. Kimura, M. Kaneko and N. Ohta: ISIJ Int. 42 (2002) 1399-1403.

14) A.J. Davenport, A.J. Dent, M. Monir, J.A. Hammons, S.M. Ghahari, P.D. Quinn and T. Rayment: J. Electrochem. Soc. 158 (2011) C111C117.

15) M. Omori: Mater. Sci. Eng. A 287 (2000) 183-188.

16) Z.A. Munir, U. Anselmi-Tamburini and M. Ohyanagi: J. Mater. Sci. 41 (2006) 763-777. 